\title{
Wildlife Agriculture Interactions, Spatial Analysis and Trade-Off Between Environmental Sustainability and Risk of Economic Damage
}

\author{
Mario Cozzi, Severino Romano, Mauro Viccaro, Carmelina Prete, \\ and Giovanni Persiani
}

\begin{abstract}
Over the last few years, wildlife damages to the agricultural sector have shown an increasing trend at the global scale. Fragile rural areas are more likely to suffer because marginal lands, which have little potential for profit, are being increasingly abandoned. Moreover, public administrations have difficulties to meet the growing requests for crop damage compensations. There is therefore a need to identify appropriate measures to control this growing trend. The specific aim of this research is to understand this phenomenon and define specific and effective action tools. In particular, the proposed research involves different steps that start from the historic analysis of damages and result in the mapping of risk levels using different tests (ANOVA, PCA and spatial correlation) and spatial models (MCE-OWA). The subsequent possibility to cluster risk results ensures greater effectiveness of public actions. The results obtained and the statistical consistency of applied parameters ensure the strength of the analysis and of costeffectiveness parameters.
\end{abstract}

\section{Introduction}

Dealing with problems related to the damages caused by wildlife to the agricultural sector involves environmental and socioeconomic sustainability issues associated with the management of natural resources.

If, on one hand, farmers are suffering due to the damages caused to crops, on the other, hunters push towards the growth of wild fauna populations for having greater hunting opportunities. This has led to conflicting interests in many European (Wenum et al. 2003; Calenge et al. 2004; Geisser and Reyer 2004; Herrero

M. Cozzi $(\bowtie) \cdot$ S. Romano $\bullet$ M. Viccaro $\bullet$ C. Prete $\bullet$ G. Persiani

School of Agricultural Sciences, Forestry, Food and Environment - SAFE, viale dell'Ateneo

Lucano 10, 85100 Potenza, Italy

e-mail: mario.cozzi@unibas.it 
et al. 2008; Thurfjell et al. 2009) and Italian areas (Brangi and Meriggi 2003; Amici et al. 2012; Serrani 2012).

Under the current agricultural-forestry conditions, the pressure exerted on agricultural crops by wild animal populations, in particular ungulates, is a major problem for the development of rural policies, as it creates a conflict between wild animals and farmers, resulting in growing costs for public administration to compensate for damages.

From an economic point of view, the damages caused to crops, especially by ungulates, are dramatically and seriously growing. Unluckily, the national bibliography does not report recent data of this phenomenon. The unique national data date back to 2004 when, according to the estimates provided by the Ungulate National Database (Carnevali et al. 2009), the total indemnified compensations amounted to about $8.9 \%^{1}$ for damages caused by ungulates. When analysing the impact of each single species, it results that, at the national level, $90 \%$ of damages are attributable to the wild boar (Sus scrofa L.).

In Basilicata region, the observed trends in relation to the economic size of damages confirm the above data. As a matter of fact, in the 6-year period from 2007 to 2012 , the damaged area doubled, shifting from about 2,800 to 5,850 ha; as a result of this increase, the estimated compensations have more than doubled, shifting from over 550,000€ till 1,134 M€. The same proportion does not unluckily apply to the compensations actually paid to private citizens that shifted from 64.7 to $39.5 \%$ of estimated compensations. At the regional level as well, there is a high incidence of wild boar that is the major damaging species, with $98 \%$ of damages caused to crops.

The conflict of interest associated with the presence of the wild boar on land, together with some objective technical difficulties (related to the quantitative estimate of populations), makes the management of this species particularly critical. Special attention is to be attached to the areas in which the use of land for agriculture or animal production is particularly important, with a great impact on crops.

As for the possible actions to undertake in order to control the expansion of wild animal populations, the literature confirms that hunting is not actually a solution. In fact, it has been found that the populations subject to strong hunting pressure increase their prolificacy (Herrero et al. 2008; Servanty et al. 2009) by bringing forward the sexual maturity of females and by increasing to two deliveries per year. Some authors (Massei and Toso 1993; Boitani et al. 1995) state that wild boar is a very adaptable species following the "r-selection" strategy (many offspring and relatively low parental care). Due to this kind of reproduction, the expansion of European wild boar populations cannot be controlled using the traditional hunting methods.

\footnotetext{
${ }^{1}$ This amount accounts for $85.56 \%$ of the ascertained damage. It results that the overall amount ascertained for damages caused by ungulates in 2004 would not be less than about $10.3 \%$.
} 
This is true for traditional hunting but not for the selective culling of the species. In fact, population control strategies can involve both selective hunting techniques (shooting from fixed positions, using dog teams that chase wild boars towards hunters (cerca technique), or the so-called girata, where a single bloodhound is used as "finder") applied by appropriately trained operators and "in vivo" catches, through self-opening fences (closed fencing), where animals are attracted by a feed bait. Closed fences are highly selective within the social groups of the population and are used to catch mostly the population of red, striped and adult females (in a decreasing order), whereas males are caught much less frequently. The selective action of traps is matching with the objective of the control, since immature and female boars are the target social groups to control the population dynamics (Toso and Pedrotti 2001).

Positive effects in the reduction of damage to agriculture have also been obtained by permanent and mobile electric fences. For the latter type, different analyses carried out in France by the ONC (Office National de la Chasse, National Hunting Service) in the 1977-1980 period have shown the technical and economic effectiveness of this practice as an active protection of crops from wild boar-caused damages, provided that some rules for installation and monitoring are complied with.

Electric fencing may be basically installed by two operational procedures: (a) as a specific protection along the boundary of the individual holding and (b) as a linear protection in boundary areas between large woodlands and typical farmlands, for separating cultivated from natural lands. If the first type might be a good solution for private landowners, the second could be particularly suitable for public administrations with an eye to long-term planning.

Among the methods reported in the literature, chemical and noise disturbances have shown significant failure, and this is due to the fact that the species adapts rapidly to these disturbances. The research is designed to (a) set up a historical geo-referenced database of the damages caused by wild animals in the area under study and (b) identify the areas at high risk of damage, on which to focus the attention and the appropriate actions.

\section{Methodology}

\subsection{ANOVA Test}

The analysis has been conducted starting from the inventory of damages recorded at the regional level in the period from 2007 to 2012. To check on the size of damages caused by ungulates, the ANOVA (analysis of variance) test was applied to the variable "total estimated compensation", taking the annualised costs of damage as source of variation.

The analysis of variance (ANOVA) is a set of statistical techniques, related to inferential statistics, used to analyse the differences between two or more groups of 
data by comparing the variability within and among the groups. The ANOVA test provides a final balance $(\mathrm{C})$, given by the ratio of the sum of squares of intergroup means to the sum of squares of intragroup means, compared with the resulting value of Fisher's $F$ with $p-1, n t-p$ degrees of freedom, among the different annuities being compared.

In this study the one-way ANOVA test has been used to assess the differences between the amounts of compensations in the 6 years under study, both at the regional level and by reference area.

The test is used to test whether the differences between the means of compensations from 2007 to 2012 are significant. In other words, the test enables to understand whether the dynamics connected with the damages caused by wildlife are due to unpredictable extraordinary events or to an existing trend.

Moreover, if conducted for different local areas, the ANOVA test enables the differentiation based on randomness and/or trends. This specific step has entailed the choice of the target area.

\subsection{Study Area}

The area relating the Parco Nazionale del Pollino is shared by three provinces and two regions, Potenza and Matera in Basilicata and Cosenza in Calabria. The total area covers nearly 193,000 ha, of which 88,650 in the Basilicata hillside. Basilicata's 24 municipalities fall within the boundaries of the Parco's territory. The peculiarity that makes this protected area a unique environment is the sudden change from the coast to the mountain that creates a very rapid sequence of environments generating as many habitats and environments suitable for number of animal and plant species.

The Basilicata's portion includes the Sinni basin and encompasses large forests, pastures and farmland areas.

Settlement areas are closely related to farming activities that identify a landscape featured by rural areas and scattered or grouped houses forming small nuclei, with a mean population density of 40 inhab. $/ \mathrm{km}^{2}$ (ISTAT 2010). The areas destined for primary production have been progressively abandoned: through the last 30 years, over one third of farmland $(37 \%)$ has not been cultivated any longer, and this surface has further reduced by $13 \%$ over the last decade only. Cultivated crops include mostly cereals, followed, to a much lower extent, by forage, vegetables, grapevine and fruit trees. Most crops are not highly remunerative, although there is a high agricultural biodiversity, made of traditional native species and varieties, among which annuals and vineyard are at high risk.

This diversification of environments forming real mosaics of structural and morphological components of the landscape combined with the protection levels ensured "ope legis" to the animal and plant species living in the protected area and creates a strong concentration of some wild animal species, thus generating severe damages to the existing agricultural systems. 


\subsection{Analysis of Damages}

In the Parco Nazionale del Pollino, about 700 compensation requests for damages were submitted from 2007 to 2012. Ninety-nine percent of them were caused by wild boars. The economic incidence is significant with mean values of about $600,000 €$ every year. ${ }^{2}$

The requests written by the landowners concerned were computerised in an electronic spreadsheet. Collected information concerned the cadastral location, the damaged area and crop, the year, the percentage of damage, the market price of the agricultural product and the estimated and indemnified compensations. Overall the database consists of 8,600 requests, each describing 19 variables. For entering the data drawn from requests in a Territorial Information System, the database was further broken down so that each record corresponded to a land parcel. Twenty-four thousand records were thus obtained. A part of them (2,720 records) were lost when they were transferred into the GIS that enabled the geographical location of the damage, once crossed with the regional cadastral database.

\subsection{Parametrisation of Damages}

Some studies conducted in Europe have shown a correlation between the size of damages in single geographical areas and the density of wildlife population (Keuling et al. 2008; Apollonio et al. 2010); however, this does not always follow proportionality criteria (Bleier et al. 2012).

Based on that, the assumption is directed towards checking whether also in the Italian areas there is a correlation between the size of damages (intensity, perpetuity and related costs) and the physical and/or structural parameters specific to the reference area (Romano and Cozzi 2008). Table 1 shows the applied parameters.

The selected parameters result from a more general evaluation, which has been validated via the statistical correlation with respect to the spatial distribution of damages.

\subsubsection{Principal Component Analysis}

To understand the dependence between the identified variables, the multivariate statistical analysis was applied using the PCA (Principal Component Analysis) (Sanguansat 2012; Bleier et al. 2012).

The PCA transforms data from a multidimensional space to a smaller space. The PCA per se does not reduce the size of the set of data. It rotates only the axes of data

\footnotetext{
${ }^{2}$ The trend is definitely rising. The requests increased from nearly 600 in 2007 till about 900 in 2009 and the estimated compensations from 458 to $829,000 €$ from 2007 to 2011 .
} 
Table 1 Parameters applied for damage evaluation

\begin{tabular}{l|l}
\hline Physical parameters & Structural parameters \\
\hline Distance from the main road & Contrast-weighted edge density (CWED) \\
Distance from the hydrographic network & Contagion index (CONTAG) \\
Distance from wooded areas & Percentage of like adjacencies (PLADJ) \\
Distance from continuous urban fabric & Aggregation index (AI) \\
Distance from urban discontinuous & Simpson diversity index (SIDI) \\
Type agrarian soil & \\
\hline
\end{tabular}

in the space along lines of maximum variance. The axis of the greater variance is said the first principal component. Another axis orthogonal to the previous and positioned to represent the subsequent greater variance is called the second principal component and so forth. The reduction in size is performed only using the first principal components as basic set for the new space, usually the components that provide an explained cumulative variance between 70 and $90 \%$. Therefore, this subspace tends to be small and may be eliminated with a minimum loss of information. If the problem is well set, the first two to three eigenvalues will be able to explain about $70 \%$ of the data variance. Input data representing different units and/or orders of magnitude should be previously standardised.

In particular, the T-mode PCA has been applied in our study. This means that each input image may be considered as a variable and what we obtain as result is not only the images of the principal components, but also the components of eigenvalues and the synthesis of eigenvectors (the list of eigenvectors associated to each eigenvalue in a column) and the percentage of explained variance.

The output is the matrix of correlation between variables, a square matrix in which the rows are the variables and columns stand for the eigenvectors of the correlation matrix. If multiplying these squared values by the associated eigenvectors, you have the matrix of loadings $([L])$ :

$$
L=\left[\begin{array}{cc}
L_{11} & L_{1 n} \\
\vdots & \vdots \\
L_{n 1} & L_{n n}
\end{array}\right]
$$

where the actual coordinates of descriptors are represented on the new axes formed by the principal components identified. The value of the eigenvector (in absolute terms) indicates the weight of each variable, i.e., the importance of each original variable in that specific eigenvector, based on which it is possible to choose the variables to reject.

\subsection{Aggregation of Criteria}

The analysis of wildlife damage hazard has been conducted by the joint use of MCE techniques and Geographical Information System (GIS). The integration of MCE 
techniques-GIS may be useful to solve conflicting situations in spatial contexts (Janssen and Rietveld 1990; Malczewski 2004) and constitutes an effective approach in the analysis of land use suitability/risk (hazard) (Yager 1988; Carver 1991; Eastman 1997; Malczewski 2004; Thill 1999; Romano and Cozzi 2006; Romano et al. 2013; Cozzi et al. 2014). This integration may be conceived as a process that combines and transforms spatial and nonspatial data (input) into a decision (output), defining a relation between input maps and the output map obtained from geographical data and decision preferences, handled according to specified decision rules (Malczewski 2004).

Among the MCE techniques, the ordered weighted averaging (OWA) was applied in this work with relative linguistic quantifiers (as proposed in Romano et al. 2013).

There are three principal components in GIS-OWA procedures: (1) criterion maps (and standardisation procedures associated to them), (2) criterion weights (and the associated procedures to define the weights of relative importance between criteria) and (3) order weights (and the procedures associated to the identification of OWA parameters) (Romano et al. 2013; Cozzi et al. 2014; Malczewski and Liu 2014). In this study, the choice of linguistic quantifiers for the definition of OWA parameters depends on whether they can best represent the decision maker's qualitative information with respect to his/her perception of the relationship between different assessment criteria. Thus, choosing the appropriate linguistic quantifiers and defining an adequate system of weights result in a wide range of risk maps (Table 2).

\section{Results}

The ANOVA test provides a Final Balance $(C)$ of 6.70 against a quantile of $F_{[5 ; 5344]}=3.02 ; p<0.05$ between the different annuities being compared. Therefore, there is a highly significant difference between the group means, i.e., between the total estimated compensations produced by wild boars in the period from 2007 to 2012 on the regional scale.

Table 2 Linguistic quantifiers

\begin{tabular}{l|l|l}
\hline Quantifiers (Q) & $\alpha$ & Calculating weights order \\
\hline All & $\alpha \rightarrow \infty$ & \multirow{2}{*}{$v_{j}=\left(\sum_{k=1}^{j} u_{k}\right)^{\alpha}-\left(\sum_{k=1}^{j-1} u_{k}\right)^{\alpha}$} \\
\cline { 1 - 2 } Almost all & $\alpha=10$ & \\
\cline { 1 - 2 } Most & $\alpha=2$ & \\
\cline { 1 - 2 } Half & $\alpha=1$ & \\
\cline { 1 - 2 } A few & $\alpha=0.5$ & \\
\cline { 1 - 2 } At least a few & $\alpha=0.1$ & \\
\cline { 1 - 2 } At least one & $\alpha \rightarrow 0$ & \\
\hline
\end{tabular}

$v_{j}$ is the weight order, $u_{k}$ is the weight criterion ordered and $\alpha$ is the parameter related to the linguistic quantifier 
Table 3 ANOVA test results

\begin{tabular}{l|l}
\hline Land areas & Fisher $F$ \\
\hline ATC 1 & $C=2.84>F_{[5 ; 149]}=2.27$ \\
\hline ATC 2 & $C=2.04<F_{[5 ; 334]}=2.24$ \\
\hline ATC 3 & $C=1.48<F_{[5 ; 566]}=2.23$ \\
\hline Gallipoli Cognato Piccole Dolomiti Lucane Park & $C=1.45<F_{[5 ; 246]}=2.25$ \\
\hline Province of Matera & $C=3.14>F_{[5 ; 1060]}=3.03$ \\
\hline Oases & $C=1.27<F_{[5 ; 8]}=3.69$ \\
\hline Murgia Materana Park & $C=0.33<F_{[5 ; 33]}=2.50$ \\
\hline Pollino National Park & $C=13.24>F_{[5 ; 2661]}=2.22$ \\
\hline Appennino Lucano Val d'Agri-Lagonegrese National Park & $C=5.01>F_{[5 ; 79]}=2.33$ \\
\hline General & $C=6.60>F_{[5 ; 5344]}=2.22$ \\
\hline
\end{tabular}

$C$ : final balance

The results of the one-way ANOVA test applied to land areas (ATC, oases, parks and provinces) show highly significant differences between different annuities for the Pollino National Park and the Appennino Lucano Val d'Agri Lagonegrese National Park that fall within no-hunting zones (Table 3). This information led the authors to focus on the Pollino National Park.

Results show that the trends of damages in Basilicata are uprising, on average, as shown in this case by the economic size of this phenomenon.

Within the Pollino National Park, out of a total damaged area of about 7,500 ha, the estimated compensation was 2.2 M€ over the 6 years. This accounted for $43 \%$ of the regional estimated compensation, of which about 1.5 million (68\% of the ascertained damage) has been paid. Cereals are the most common crops, in terms of cropped area, and are the most affected ones, followed, to a lower extent, by protein crops, vegetables, grapevine and olive, in addition to some limited cases of woody crops. Another interesting element concerns the damage frequency on the same plot. In fact, it has been noted that a particle out of three is involved more than once by the damage over the 6 years considered. This induces the authors to consider that there is a systematic approach, a species custom to return to the same plot. This is maybe due to the fact that the plot shows cropping and localisation conditions that are favourable to the damage.

This originates the assumption that it is possible to trace back the setting up of an appropriate logical model, aimed at identifying the areas with a greater propensity to the damage.

To this end, 15 explanatory parameters have been identified, including 6 physical and 9 structural parameters, on which a correlation has been made with respect to the damages occurred. It results that only 11 are appropriately correlated, as shown in Table 4.

The correlation equations reported in Table 4 have been utilised to standardise the variables.

The assessment of the dependence/overlapping between the variables performed by the PCA has shown that $78 \%$ of cumulative variance is obtained in the first 


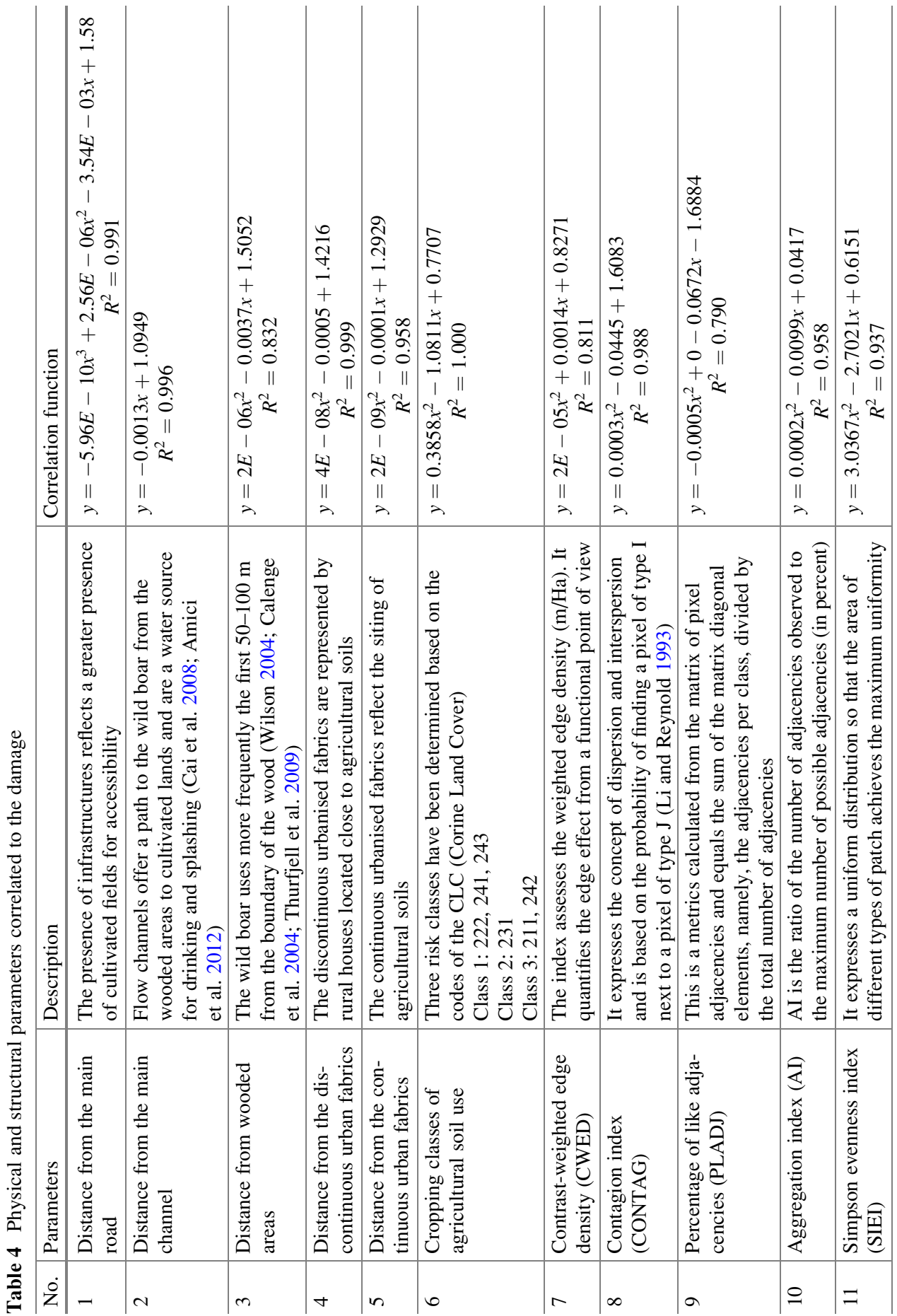


component and up to $87 \%$ may be achieved if considering the second component. The values obtained show that the variables used are not correlated to each other and, therefore, basically applicable as criteria for the multicriteria analysis. In particular, based on the first two components, the matrix of loadings has been calculated, and a single evaluation criterion has been eliminated (crop classes of agricultural land use).

The next step was to attribute to the ten remaining criteria the weights of relative importance via the Analytical Hierarchy Process, AHP (Saaty 1977, 1980; Malczewski 2004). More specifically, in the attribution of weights to different criteria, it was considered to take into account the $R^{2}$ derived from standardisation functions: the greater correlation of the criterion to the damage hazard is given a greater weight and vice versa. It is obvious that since all criteria have not a high $R^{2}$ $\left(R^{2} \rightarrow 1\right)$ so that the aggregation model gives back a reliable result, it is advisable that all or most criteria are satisfied. Based on that, the linguistic quantifiers All, Almost all and Most have been chosen for calculating order weights and implementing the OWA aggregation model (Fig. 1). When comparing the risk maps obtained by the actual damage data, it is expected that high-risk values (close to 1) are obtained: based on this consideration, the map connected with the Most quantifier has been chosen as the final one, since $75 \%$ of higher hazard values correspond to actual damages.

Reclassifying this map using Chen's method (Chen and Hwang 1992) (Fig. 2), areas may be grouped as areas at no hazard (0-0.25), low hazard $(0.25-0.56)$, medium hazard (0.56-0.92) and high hazard $(>0.92)$.

It is important to restate that the area under analysis is only the portion of the parkland sited in Basilicata, but the analysis carried out is intended to be a general predictive model of the damage hazard.

Based on the guidelines for wild boar management in protected areas, set out by the INFS (National Institute for Wildlife) for the Ministry of the Environment and Protection of Land and Sea, the envisaged wild boar management might be
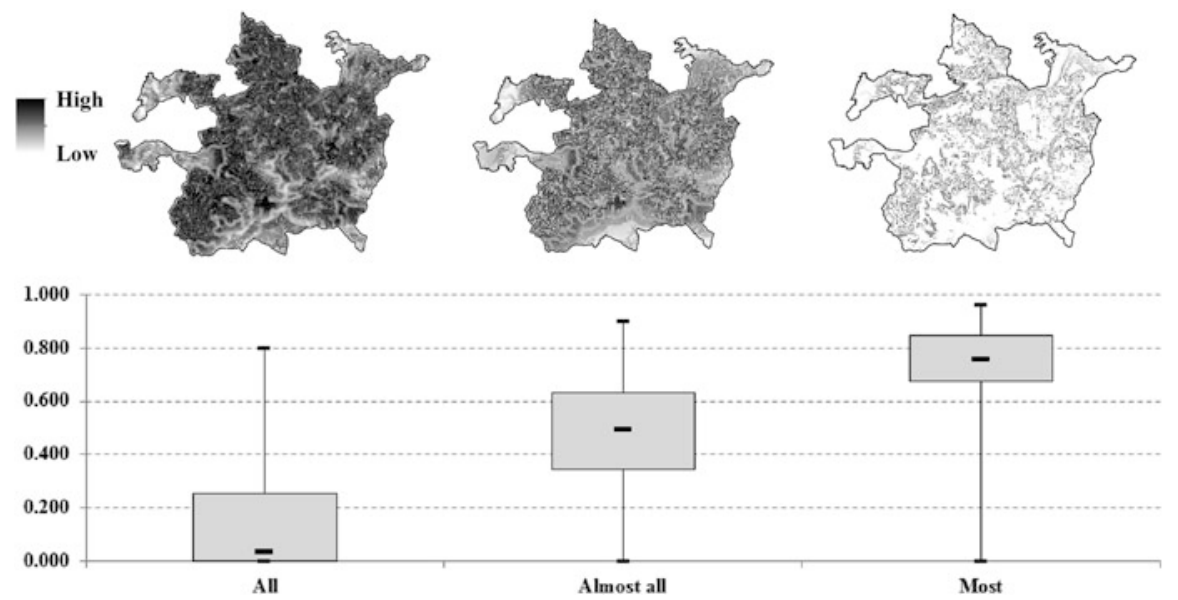

Fig. 1 MCE-OWA maps and Box Plot 


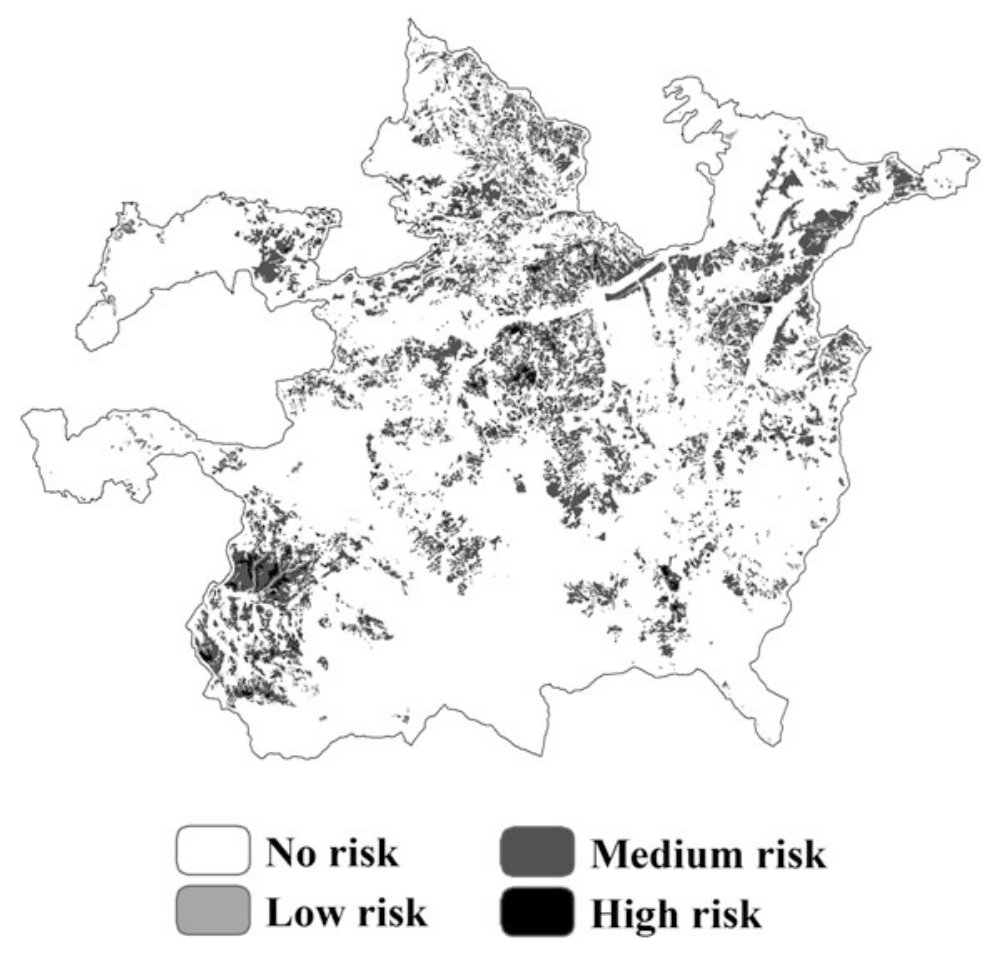

Fig. 2 Hazard risk reclassified

implemented by diversified actions, and methods somehow integrated with each other.

Therefore, based on the hazard map and considering only the high-risk class, seven larger areas were identified (Fig. 3) and tested for approximate damages against the costs required to develop an appropriate preventive system to hamper the transit of wild animals, for which, as previously mentioned, the most reliable system is represented by artificial separators, such as fences or electric obstacles. From the hazard map, the area and perimeter of these systems were extrapolated, and their semi-perimeters were taken into account, since the area does not require to be wholly enclosed. The costs have been obtained on the basis of wholesome (and for large amounts) estimates requested to national tradesmen. The resulting values are ranged between 500 and $1,500 € / \mathrm{km}$. This size has been confirmed by the recent tests carried out within the 2007-2013 ${ }^{3}$ Emilia Romagna Rural Development Plan that indicates values fluctuating between 765 and $890 € / \mathrm{km}$, depending on whether it is connected or not to the power network.

It results that the total costs, calculated from the seven higher risk areas, where the total surface covers 155 ha and the semi-perimeter $28 \mathrm{~km}$, range from 21,615 to $24,618 €$. To these values it is necessary to add the cost for the installation and

\footnotetext{
${ }^{3}$ www.agenter.it/pdf/fuorilafauna.pdf
} 


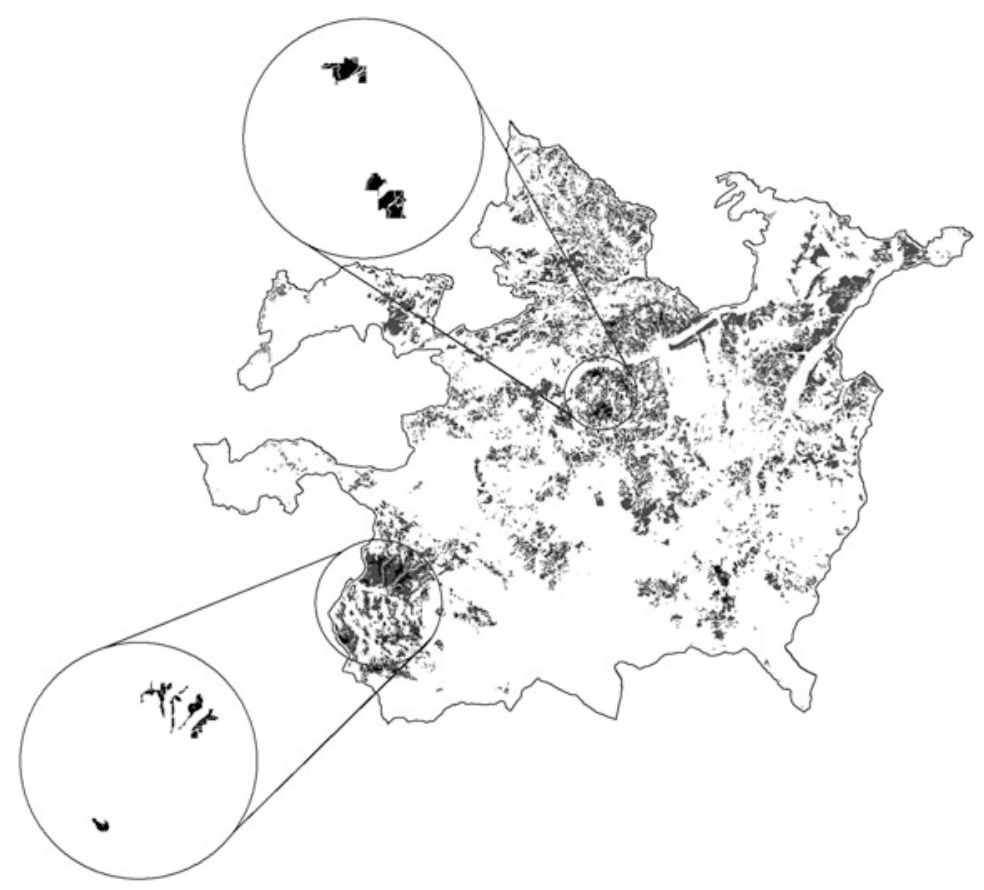

Fig. 3 Cluster areas

maintenance of fences (brush cutting, periodical restoration, repair of any breaks) that would certainly involve higher costs, if fully outsourced. For comparative purposes, the equivalent cost incurred by the public administration for compensation was calculated and resulted to be $32,500 €$ on average for about 155 ha, concerning the surface of considered clusters.

Moreover, for the numerical control of wild boars, a comprehensive action plan involves a species-selective culling scheme; from the hazard map it is possible to plan the distribution of selective hunters across the area ${ }^{4}$ based on the high-risk zones proportioned to municipal areas, so as to optimise the actions and resources made available by the public administration (Table 5 and Fig. 4).

\section{Conclusions}

Based on the historical data of wildlife damages to crops, it results that the occurrence of this phenomenon is generally raising. The damaged area between 2007 and 2012 has more than doubled, shifting from about 2,800 to 5,850 ha.

\footnotetext{
${ }^{4}$ The number of selective hunters has been drawn from the "Regulation for wild boar control" $\mathrm{N}^{\circ}$ 30 of 29/04/2011 that involves the recruitment of 370 selective hunters across the whole area of Pollino National Park.
} 
Table 5 Distribution of selective hunters across the region

\begin{tabular}{|c|c|c|c|c|c|}
\hline & Municipality & $N$ & & Municipality & $N$ \\
\hline 1 & Calvera & 12 & 13 & Lauria & 0 \\
\hline 2 & Carbone & 5 & 14 & Noepoli & 4 \\
\hline 3 & Castelluccio Inferiore & 0 & 15 & Rotonda & 20 \\
\hline 4 & Castelluccio Superiore & 0 & 16 & San Costantino Albanese & 3 \\
\hline 5 & Castelsaraceno & 0 & 17 & San Paolo Albanese & 3 \\
\hline 6 & Castronuovo di Sant'Andrea & 11 & 18 & San Severino Lucano & 5 \\
\hline 7 & Cersosimo & 3 & 19 & Senise & 0 \\
\hline 8 & Chiaromonte & 16 & 20 & Teana & 15 \\
\hline 9 & Episcopia & 15 & 21 & Terranova di Pollino & 3 \\
\hline 10 & Fardella & 5 & 22 & Viggianello & 13 \\
\hline 11 & Francavilla in Sinni & 17 & 23 & San Giorgio Lucano & 1 \\
\hline \multirow[t]{2}{*}{12} & Latronico & 0 & 24 & Valsinni & 0 \\
\hline & Total & & & & 152 \\
\hline
\end{tabular}

$N$ Numbers of hunters

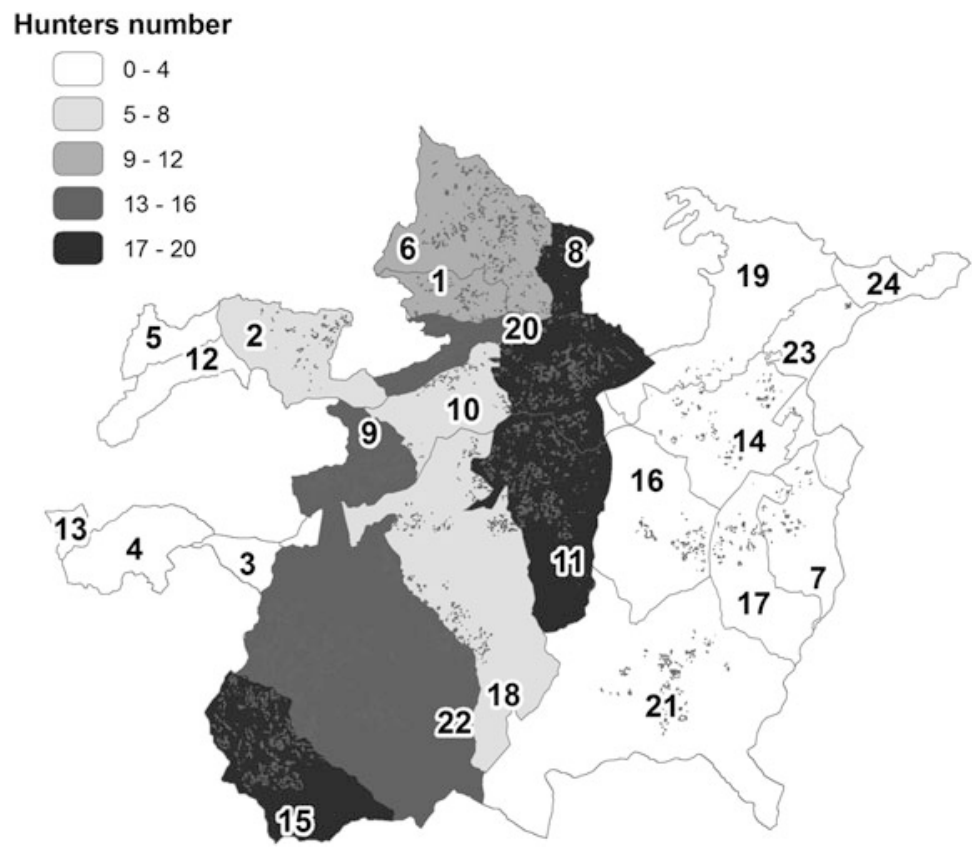

Fig. 4 Distribution of selective hunters by municipality

Besides a growing discontent among farmers, compensation costs have generally increased for public administrations that, in the case of Basilicata region, amounted to $1,134 \mathrm{M} €$ in 2012 . 
It is urgent to take actions to prevent and even control this phenomenon. This can be done on the basis of a careful analysis of the context area and of the prevailing trends. In this framework it may be useful to apply spatialised analysis models, aimed at facilitating land planning and governance choices, so as to optimise the existing planned actions to mitigate damages to farms.

This study has shown that from the identification of land parameters connected with wildlife damages, it is possible to build a map representing the areas at high damage hazard, where actions should be targeted.

On the other hand, we need to carry out direct field surveys to check the actual effectiveness of what is proposed by the applied methodology.

The analysis, conducted on the Pollino National Park, has resulted in the spatial identification of the agricultural areas most sensitive to wildlife damages.

The results obtained show that targeted actions might be taken to downsize the effects of crop damages in the long-term perspective. The effectiveness of actions depends, however, on other factors as well that need to be controlled. For example, no fence or obstacle could be overcome if there is not sufficient feed supply in natural environments. Therefore these control actions may be successful only if they are integrated by other simultaneous or alternative actions throughout the year (fodder in periods of feed deficit, selective hunting).

Over the last 15 years, despite the actions undertaken by the managing body for the solution of the problem, ${ }^{5}$ it seems that the applied approach has been directed towards an "individualist" solution through compensations and/or incentives for prevention systems addressed to single farmers. No linear protection fencing systems have been used in the bordering areas between forests and agricultural zones nor other "community" systems based on long-term planning have been implemented to know and understand the phenomenon and obtain a detailed picture of the distribution, the size and the evolutionary trends of the species across the region (no data are available so far on these parameters). This would be useful to identify the target densities and the withdrawal densities compatible with economic damages. In this sense, there are no absolute indications of optimal density and size, and each environmental site necessitates its own solution, which is to be sought by trial and error (adaptive management).

Today's objective is to achieve a kind of "agroecological" balance that means a sustainable balance between the amount of social and economic costs of crop damage - in terms of refund and prevention - and a sufficient population size for maintaining the ecological role of the species in the protected ecosystem (Mattioli et al. 1995).

In conclusion, managing a wild boar population means adapting its size and structure to the capacity of the environment while minimising the associated economic and environmental damages and the subsequent social conflicts.

\footnotetext{
5 "Regulation for the granting of financial aid on the protection of wild boar-caused damages" $\mathrm{N}^{\circ}$ 122 of 15/10/1998 and "Wild boar management plan" $N^{\circ} 23$ of 27/10/2006, $N^{\circ} 941$ of 06/11/2012 for the granting of financial aid aimed at setting up fencing for preventing damages to crops caused by wild boars and deers in the Pollino National Park.
} 
Future developments of the applied model will involve defining costeffectiveness indices to demonstrate the monetary and social effectiveness of both analyses and proposed actions.

Open Access This chapter is distributed under the terms of the Creative Commons Attribution Noncommercial License, which permits any noncommercial use, distribution, and reproduction in any medium, provided the original author(s) and source are credited.

\section{References}

Amici A, Serrani F, Rossi CM, Primi R (2012) Increase in crop damage caused by wild boar (Sus scrofa L.): the "refuge effect". Agron Sustain Dev 32:683-692

Apollonio M, Andersen R, Putman R (eds) (2010) European ungulates and their management in the 21 st century. Cambridge University Press, Cambridge

Bleier N, Lehoczki R, Újváry D, Szemethy L, Csányi S (2012) Relationships between wild ungulates density and crop damage in Hungary. Acta Theriol 57:351-359

Boitani L, Trapanese P, Mattei L, Nonis D (1995) Demography of a wild boar (Sus scrofa L.) population in Tuscany, Italy. Gibier Faune Sauvage 12(2):109-132

Brangi A, Meriggi A (2003) Espansione del cinghiale (sus scrofa) e danni alle coltivazioni in un'area delle prealpi occidental. Hystrix Ital J Mammal (ns) 14(1-2):95-105

Cai J, Jiang Z, Zeng Y, Li C, Bravery BD (2008) Factors affecting crop damage by wild boar and methods of mitigation in a giant panda reserve. Eur J Wildl Res 54(4):723-728

Calenge C, Maillard D, Fournier P, Fouque C (2004) Efficiency of spreading maize in the garrigues to reduce wild boar (Sus scrofa) damage to Mediterranean vineyards. Eur J Wildl Res 50:112-120

Carnevali L, Pedrotti L, Riga F, Toso S (2009) Banca Dati Ungulati: status, distribuzione, consistenza, gestione e prelievo venatorio delle popolazioni di Ungulati in Italia. Rapporto 2001-2005. Biol Cons Fauna 117:1-168

Carver SJ (1991) Integrating multi-criteria evaluation with geographical information systems. Int J Geogr Inf Syst 5(3):321-339

Chen SJ, Hwang CL (1992) Fuzzy multiple attribute decision making: methods and applications. Springer, Berlin

Cozzi M, Di Napoli F, Viccaro M, Fagarazzi C, Romano S (2014) Ordered weight averaging multicriteria procedure and cost-effectiveness analysis for short rotation forestry in the Basilicata region, Italy. Int J Global Energy Issues 37(5):282-303

Eastman JR (1997) Idrisi for windows, version 2.0: tutorial exercises. Graduate School of Geography, Clark University, Worcester, MA

Geisser H, Reyer HU (2004) Efficacy of hunting, feeding, and fencing to reduce crop damage by wild boars. J Wildl Manag 68:939-946

Herrero J, García-Serrano A, García-Gonzalez R (2008) Reproductive and demographic parameters in two Iberian wild boar Sus scrofa populations. Acta Theriol 53(4):355-364

ISTAT (2010) Censimento Agricoltura 2010. http://dati-censimentoagricoltura.istat.it. Accessed Nov 2014

Janssen R, Rietveld P (1990) Multicriteria analysis and geographical information systems: an application to agricultural land use in the Netherlands. In: Scholten HJ, Stillwell JCH (eds) Geographical information systems for urban and regional planning. Kluwer Academic, Dordrecht, pp 129-139

Keuling O, Stier N, Roth M (2008) How does hunting influence activity and spatial usage in wild boar Sus scrofa L.? Eur J Wildl Res 54(4):729-737 
Li H, Reynold JF (1993) A new contagion index to quantify spatial patterns of landscapes. Landsc Ecol 8(3):155-162

Malczewski J (2004) GIS-based land-use suitability analysis: a critical overview. Prog Plan 62 (1):3-65

Malczewski J, Liu X (2014) Local ordered weighted averaging in GIS-based multicriteria analysis. Ann GIS 20(2):117-129

Massei G, Toso S (1993) Biologia e gestione del cinghiale. Istituto Nazionale per la Fauna Selvatica. Documenti tecnici, 5

Mattioli M, Apollonio V, Mazzarone E, Centofanti E (1995) Wolf food habits and wild ungulate availability in the Foreste Casentinesi National Park, Italy. Acta Theriol 40:387-402

Romano S, Cozzi M (2006) Il governo del territorio e la conservazione delle risorse: l'uso dei modelli geografici multicriteriali per la valutazione del rischio socio economico e ambientale degli incendi boschivi. Rivista di Economia Agraria 61(3):365-400

Romano S, Cozzi M (2008) Valutazione delle trasformazioni del suolo e delle dinamiche in atto mediante analisi territoriale e metriche statistiche: il caso dell'hinterland potentino. Basilicata Agribusiness Paesaggio \& Ambiente 11(2):98-108

Romano S, Cozzi M, Viccaro M, Di Napoli F (2013) The green economy for sustainable development: a spatial multi-criteria analysis-ordered weighted averaging approach in the siting process for short rotation forestry in the Basilicata Region, Italy. Ital J Agron 8 (3):258-267

Saaty TL (1977) A scaling method for priorities in hierarchical structures. J Math Psychol 15:234-281

Saaty TL (1980) The analytic hierarchy process: planning, priority, setting and resource allocation. McGraw Hill, New York

Sanguansat P (2012) Two-dimensional principal component analysis and its extensions. INTECH Open Access Publisher

Serrani F (2012) Interazione tra il cinghiale (Sus scrofa) e le attività antropiche con particolare riferimento al sistema agro-silvo-pastorale. PhD Thesis

Servanty S, Gaillard JM, Toïgo C, Brandt S, Baubet E (2009) Pulsed resources and climateinduced variation in the reproductive traits of wild boar under high hunting pressure. J Anim Ecol 78(6):1278-1290

Thill JC (1999) Spatial multicriteria decision-making and analysis: a geographic information sciences approach. Ashgate, New York

Thurfjell H, Ball JP, Åhlén PA, Kornacher P, Dettki H, Sjöberg K (2009) Habitat use and spatial patterns of wild boar Sus scrofa (L.): agricultural fields and edges. Eur J Wildl Res 55 (5):517-523

Toso S, Pedrotti L (2001) Linee guida per la gestione del cinghiale (Sus scrofa) nelle aree protette. Quaderni di conservazione della natura 3

Wenum JHV, Wossink GAA, Renkema JA (2003) Location-specific modeling for optimizing wildlife management on crop farms. Ecol Econ 48:395-407

Wilson CJ (2004) Rooting damage to farmland in Dorset, southern England, caused by feral wild boar Sus scrofa. Mammal Rev 34:331-335

Yager RR (1988) On ordered weighted averaging aggregation operators in multi-criteria decision making. IEEE Trans Syst Man Cybern 18(1):183-190, http://dati-censimentopopolazione.istat.it 